\title{
BMJ Open Local and systemic morbidities of de novo metastatic prostate cancer in Singapore: insight from 685 consecutive patients from a large prospective Uro- oncology registry
}

\author{
Yu Guang Tan, ${ }^{1}$ Leonard Pang (D) , ${ }^{2}$ Farhan Khalid, ${ }^{2}$ Randy Poon (D) , \\ Hong Hong Huang, ${ }^{1}$ Kenneth Chen, ${ }^{1}$ Kae Jack Tay, ${ }^{1}$ Weber Lau, ${ }^{1}$ \\ Christopher Cheng, ${ }^{1}$ Henry Ho, ${ }^{1}$ John Yuen ${ }^{1}$
}

To cite: Tan YG, Pang L, Khalid F, et al. Local and systemic morbidities of de novo metastatic prostate cancer in Singapore: insight from 685 consecutive patients from a large prospective Urooncology registry. BMJ Open 2020;10:e034331. doi:10.1136/ bmjopen-2019-034331

- Prepublication history for this paper is available online. To view these files, please visit the journal online (http://dx.doi. org/10.1136/bmjopen-2019034331).

Received 29 September 2019

Revised 29 January 2020

Accepted 30 January 2020

\section{Check for updates}

(c) Author(s) (or their employer(s)) 2020. Re-use permitted under CC BY-NC. No commercial re-use. See rights and permissions. Published by BMJ.

${ }^{1}$ Department of Urology, Singapore General Hospital, Singapore, Singapore

${ }^{2}$ Yong Loo Lin School of Medicine, National University of Singapore, Singapore, Singapore

Correspondence to Dr Leonard Pang; leonardpjw@yahoo.com.sg

\section{ABSTRACT}

Objective To evaluate the incidence and management of local and systemic complications afflicting patients with de novo metastatic prostate cancer (mPCa) in Singapore.

Design Retrospective analysis of a large prospective Urooncology registry of $\mathrm{mPCa}$.

Setting This study is carried out in a tertiary hospital in Singapore.

Participants We reviewed our institution's prospectively maintained database of 685 patients with mPCa over a 20year period (1995-2014). Patients with non-mPCa or those progressed to metastatic disease after previous curative local treatments were excluded.

Primary and secondary outcome measures The primary outcome was to evaluate the systemic and local morbidity rates associated with $\mathrm{mPCa}$. Local complication was defined as the need for palliative procedures to relieve urinary obstruction, worsening renal function or refractory haematuria, while systemic complication was related to radiographic evidence of skeletal-related pathological fractures. Secondary outcomes analysed were the management and overall survival patterns over 20 years.

Results 237 (34.6\%) patients required local palliative treatments. $88(12.8 \%)$ patients presented with acute urinary retention, 23 patients $(9.7 \%)$ required repetitive local palliative treatments. On multivariate analyses, prostate-specific antigen $>100(p=0.02)$ and prostate volume $>50 \mathrm{~g}(\mathrm{p}=0.03)$ were independent prognostic factors for significant obstruction requiring palliative procedures. 118 (17.2\%) patients developed skeletal fractures, with poor Eastern Cooperative Oncology Group Performance (ECOG) status $(p=0.01)$ and high volume bone metastasis $(p<0.01)$ independently predictive of skeletal fractures. Altogether, $653(95.3 \%)$ patients received androgen deprivation therapy (ADT), with the median time to castrate resistance of 21.4 months (IQR 7-27). The median overall survival was 45 months (IQR 20-63), with prostate cancer mortality of $81.4 \%$. Improved overall survival was observed from 41.6 months (19951999) to 47.8 months $(2010-2014)(p<0.01)$.

Conclusion Morbidities and complications arising from $\mathrm{mPCa}$ are more common and debilitating than we thought,
Strengths and limitations of this study

- Large series of de novo metastatic prostate cancer (mPCa) from a prospectively maintained cancer registry.

- This study looked at the local and systemic complications of $\mathrm{mPCa}$, an aspect that had not been well covered in the literature.

- The data were derived from a single tertiary institution and the analysis was retrospective in nature.

- The study period precluded the availability of validated quality-of-life assessment tools, which may better reflect well being.

- This study precluded the routine use of early systemic therapies in hormone-sensitive prostate cancer, which may affect the prevalence of local and systemic complications.

often requiring immediate palliative treatments, while many necessitate repeated interventions with progression.

\section{INTRODUCTION}

There is a general trajectory of increase in prostate cancer (PCa) incidence across developed countries with the advent of PCa screening. ${ }^{2}$ In spite of the ongoing screening efforts, a significant proportion of patients still presents with de novo metastatic prostate cancer (mPCa). ${ }^{3}$ For these patients, their quality of life is significantly affected not only due to the systemic effects of metastatic disease but also due to local progression of the cancer which leads to significant local morbidities. ${ }^{45}$ Moreover, with a rapidly ageing population in many countries, the incidence of PCa-and likely de novo $\mathrm{mPCa}$-is set to rise even further, possibly festering into a significant healthcare concern in the foreseeable future. ${ }^{6}$ 
With much of the PCa research and treatments being driven towards understanding the survival outcomes of mPCa, the last decade has seen an improved cancer survival with newer anti-androgen and chemotherapeutic regimens. However, much is yet to be learnt regarding the magnitude of clinical problems in managing the complications and morbidities of mPCa, be it local (urinary obstruction, refractory haematuria) or systemic (skeletalrelated events (SREs)). One study has revealed the prevalence of SRE to be close to $50 \%,{ }^{7}$ bringing about an adverse impact of the quality and quantity of life on these patients. $^{89}$

The objective of this study is to evaluate the incidence and management of systemic and local complications afflicting patients who present with de novo mPCa over a contemporary period of two decades based on a large prospectively maintained PCa database in a large tertiary institution.

\section{METHODS AND MATERIALS}

This is an Institution Review Board-approved (SingHealth IRB: 2009/1053/D) retrospective study of a large cohort of consecutive patients $(n=685)$ presented with de novo mPCa from a large prospectively maintained PCa database over a 20-year period (1995-2014). Patients with non-mPCa or those who progressed to metastatic disease after previous curative local treatment (prostatectomy or radiotherapy) were excluded from our study. Apart from routine digital rectal examination and prostatespecific antigen (PSA) levels, all patients underwent a bone scan and CT scan of the thorax, abdomen and pelvis as part of the complete metastatic workup. High volume disease was defined by the CHAARTED database, ${ }^{10}$ which included patients with visceral metastases or $\geq 4$ bone lesions with $\geq 1$ beyond the vertebral bodies and pelvis. Five hundred and twenty-eight $(77.1 \%)$ patients had prostatic tissues sampled for histological confirmation of adenocarcinoma, while $55(8.0 \%)$ patients underwent metastatic biopsies to confirm the diagnosis of mPCa and the remaining $102(14.9 \%)$ patients were treated with presumptive mPCa (PSA $>100$ with radiological evidence of metastasis) without histology. All patients were routinely followed up every 3-6 monthly, with blood tests for PSA and testosterone levels at each visit. Additional tests, which included imaging, were performed based on new symptoms or clinical findings, or on the primary physician's decision.

\section{Study outcomes}

Baseline patient comorbidities, demographics and cancer characteristics were collected. The primary outcome was to evaluate the systemic and local morbidity rates associated with mPCa. The local complication was defined as the need for palliative operative procedures to relieve urinary obstruction, worsening renal function or refractory haematuria, while the systemic complication was related to radiographic evidence of skeletal-related pathological fractures. The secondary outcome analysed was overall survival patterns over the 20 -year period, with interim 5 yearly analyses.

Statistical analyses were performed using SPSS V.20. The relationship between clinicopathological features and complications of mPCa was calculated with the $\chi^{2}$ test. Multivariate analyses were performed using logistic regression models to identify prognostic factors for local and systemic complications. Cox regression models were used to identify independent predictors of overall survival. Kaplan-Meier models were designed to illustrate the various survival curves. All tests were two sided with $\mathrm{p}<0.05$ considered to be statistically significant.

\section{Patient and public involvement}

Patients were not directly involved in the design, planning and conducting of this study.

\section{RESULTS}

Table 1 shows the patient demographics, clinical presentations and disease characteristics. The median age of diagnosis was 73 (IQR 66-78) years old, with a preponderance of Chinese racial group (82.5\%). Eighty-two patients $(12.0 \%)$ had Eastern Cooperative Oncology Group Performance (ECOG) status $\geq 2$. At the initial presentation, 480 patients $(70.2 \%)$ had PSA levels $>100 \mathrm{ng} / \mathrm{mL}$, with predominant Gleason $\geq 8(65.9 \%)$. Bone involvement $(85.4 \%)$ was the most common site of distal metastasis. Four hundred and thirty-five $(63.5 \%)$ patients had high volume bone metastasis and seventy-seven (11.2\%) patients had visceral involvement (table 1). Six hundred and twelve $(89.3 \%)$ patients were symptomatic, with bone pain $(81.2 \%)$, urinary obstruction $(42.3 \%)$ and haematuria $(27.0 \%)$ being the most common presentations. One hundred and eighteen $(17.2 \%)$ patients had significant renal impairment (serum creatinine $>300 \mathrm{mmol} / \mathrm{L}$ ).

\section{Primary outcomes}

Of the 685 patients analysed, 237 (34.6\%) patients required local palliative treatments, of which $88(12.8 \%)$ patients presented with acute urinary retention that necessitated early surgical treatment to relieve urinary obstruction (table 2). Transurethral prostate resection (TURP) was the most common performed procedure (88.2\%), followed by percutaneous nephrostomy (7.6\%), transurethral bladder neck incision $(2.6 \%)$ and ureteral stent insertion (1.7\%) (figure 1). The median time to palliative surgery was 7 months (IQR 3-16) from the initial diagnosis. Another 23 patients $(9.7 \%)$ required repetitive local palliative surgeries. On multivariate analyses, initial PSA $>100(\mathrm{p}=0.02$, HR $1.86,95 \%$ CI 1.33 to $2.63)$ and prostate volume in excess of $50 \mathrm{~g}(\mathrm{p}=0.03$, HR $6.11,95 \%$ CI 4.21 to 26.22 ) were independent prognosticators of significant bladder outlet obstruction requiring local palliative procedures (table 3 ).

Separately, 118 (17.2\%) patients had suffered from skeletal fractures, at a median time of 15 months (IQR 10-19) 
Table 1 Patient demographics and disease characteristics

\section{Number of \\ patients,}

median $\quad \% \quad$ Quartiles

\begin{tabular}{|c|c|c|}
\hline \multicolumn{3}{|l|}{ Race } \\
\hline Chinese & 565 & 82.5 \\
\hline Malay & 66 & 9.6 \\
\hline Indian & 39 & 5.7 \\
\hline Others & 15 & 2.2 \\
\hline
\end{tabular}

$\begin{array}{rrr}0-1 & 603 & 88.0 \\ 2-4 & 82 & 12.0\end{array}$

\begin{tabular}{|c|c|c|c|}
\hline \multicolumn{4}{|c|}{ Year of diagnosis } \\
\hline 1995-1999 & 129 & 18.8 & \\
\hline 2000-2004 & 120 & 17.6 & \\
\hline 2005-2009 & 165 & 24.1 & \\
\hline 2010-2014 & 271 & 39.5 & \\
\hline Age (years) & 73 & & $66-78$ \\
\hline \multicolumn{4}{|c|}{ Method of diagnosis } \\
\hline TRUS & 385 & 56.2 & \\
\hline TURP & 143 & $20 . c$ & \\
\hline $\begin{array}{l}\text { Biopsy of } \\
\text { metastasis }\end{array}$ & 55 & $8 .($ & \\
\hline Radiological & 102 & $14 . \varsigma$ & \\
\hline
\end{tabular}

PSA stratification

\begin{tabular}{|c|c|c|}
\hline $0-20$ & 60 & 8.8 \\
\hline $20.1-50$ & 61 & 8.9 \\
\hline $50.1-100$ & 84 & 12.3 \\
\hline$>100$ & 480 & 70.2 \\
\hline \multicolumn{3}{|l|}{ Gleason score } \\
\hline 7 & 180 & 34.1 \\
\hline $8-10$ & 348 & 65.9 \\
\hline \multicolumn{3}{|l|}{ Metastatic sites } \\
\hline Bone & 585 & 85.4 \\
\hline Lymph node & 134 & 19.6 \\
\hline Lungs & 52 & 6.7 \\
\hline Liver & 18 & 1.8 \\
\hline Brain & 7 & 1.0 \\
\hline $\begin{array}{l}\text { High volume bone } \\
\text { metastasis }\end{array}$ & 442 & 64.5 \\
\hline Visceral metastasis & 60 & 8.7 \\
\hline
\end{tabular}

ECOG PS, Eastern Cooperative Oncology Group Performance Status; PSA, prostate-specific antigen; TRUS, transrectal ultrasound; TURP, transurethral resection of prostate;

from initial diagnosis. On multivariate analysis, poor ECOG status ( $\mathrm{p}=0.01, \mathrm{HR} 4.29,95 \%$ CI 1.85 to 13.32$)$ and high volume bone metastasis $(\mathrm{p}<0.01$, HR $3.27,95 \% \mathrm{CI}$
Table 2 Local and systemic complications of de novo metastatic prostate cancer

\begin{tabular}{|c|c|c|c|}
\hline & $\begin{array}{l}\text { Number of } \\
\text { patients, } \\
\text { median }\end{array}$ & $\%$ & Quartiles \\
\hline Symptomatic & 612 & 89.3 & \\
\hline \multicolumn{4}{|l|}{ Symptom manifestations } \\
\hline Bone pain & 556 & 81.2 & \\
\hline Haematuria & 185 & 27.0 & \\
\hline Urinary obstruction & 290 & 42.3 & \\
\hline Urinary incontinence & 48 & 7.0 & \\
\hline Renal impairment $(\mathrm{Cr}>300)$ & 118 & 17.2 & \\
\hline $\begin{array}{l}\text { Palliative treatment for } \\
\text { urinary obstruction }\end{array}$ & 237 & 34.6 & \\
\hline $\begin{array}{l}\text { Immediate palliative } \\
\text { treatment required }\end{array}$ & 88 & 12.8 & \\
\hline $\begin{array}{l}\text { Time to palliative } \\
\text { treatment, months }\end{array}$ & 7 & & $3-16$ \\
\hline $\begin{array}{l}\text { Repetitive palliative } \\
\text { treatment }\end{array}$ & 23 & 9.7 & \\
\hline Skeletal fractures & 118 & 17.2 & \\
\hline $\begin{array}{l}\text { Time to skeletal fractures, } \\
\text { months }\end{array}$ & 15 & & $10-19$ \\
\hline
\end{tabular}

1.46 to 7.36 ) were independently associated with a higher likelihood of fractures (table 3 ).

\section{Secondary outcomes}

Altogether, 653 (95.3\%) patients received androgen deprivation therapy (ADT), with a preponderance $(61.7 \%)$ of medical castration by the luteinizing hormone-releasing hormone (LHRH) agonist administration. No patient received early docetaxel at hormone-sensitive prostate cancer (HSPC) as this was not routinely practised before the CHAARTED data published in 2015. The median time to the development of castrate-resistance prostate cancer (CRPC), according to the Prostate Cancer Work Group 2 (a repeat confirmatory PSA rise of $\geq 25 \%$ above nadir and $2 \mathrm{ng} / \mathrm{mL}$ above nadir, or radiological evidence of disease progression, with a castrate testosterone level

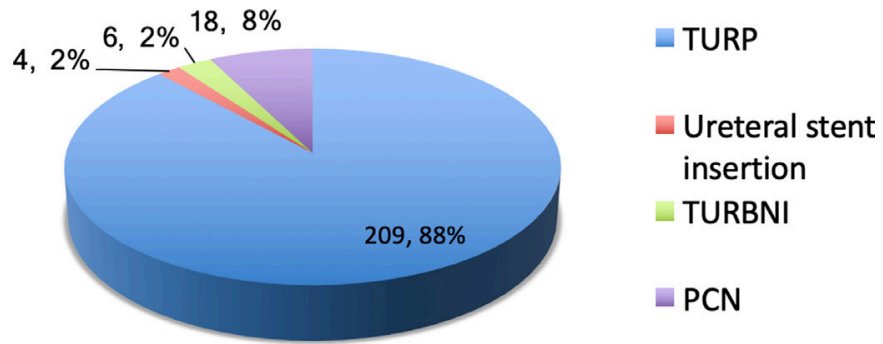

TURP: transurethral resection of prostate; TURBNI: transurethral bladder neck incision; PCN: percutaneous nephrostomy

Figure 1 Type of palliative treatments for urinary obstruction. TURP, transurethral resection of prostate; TURBNI, transurethral bladder neck incision; PCN, percutaneous nephrostomy. 


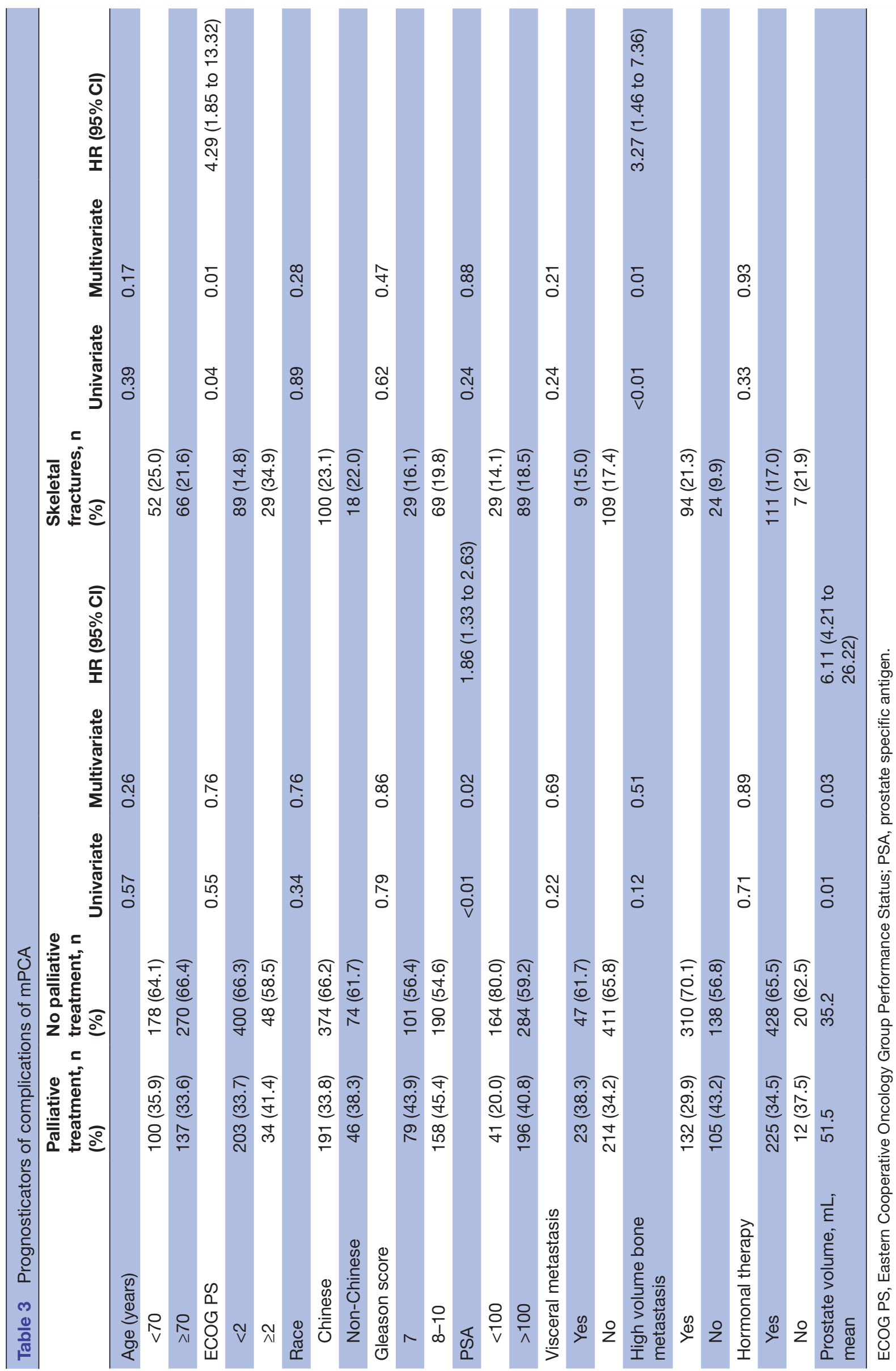


Table 4 Factors associated with overall survival

Univariate Multivariate $\mathrm{HR} \quad 95 \% \mathrm{Cl}$

\begin{tabular}{lrrrr}
\hline Age $\geq 70$ years & 0.01 & 0.74 & & \\
ECOG PS $\geq 2$ & $<0.01$ & $<0.01$ & 2.08 & 1.26 to 3.46 \\
Race & 0.19 & 0.44 & & \\
\hline
\end{tabular}

Chinese

$\begin{array}{lllll}\text { Non-Chinese } & & & & \\ \text { Gleason score } & <0.01 & <.01 & 2.46 & 1.61 \text { to } 3.77\end{array}$

$\geq 8$

\begin{tabular}{lcccc} 
PSA $>100$ & 0.43 & 0.17 & & \\
$\begin{array}{l}\text { Visceral } \\
\text { metastasis }\end{array}$ & 0.02 & 0.04 & 1.67 & 1.25 to 2.19 \\
$\begin{array}{l}\text { High volume } \\
\text { bone metastasis }\end{array}$ & $<0.01$ & $<0.01$ & 1.84 & 1.48 to 2.38 \\
$\begin{array}{l}\text { Hormonal } \\
\text { therapy }\end{array}$ & 0.04 & 0.16 & & \\
$\begin{array}{l}\text { Palliative } \\
\text { chemotherapy }\end{array}$ & 0.03 & 0.09 & & \\
$\begin{array}{l}\text { Palliative } \\
\text { treatment }\end{array}$ & 0.85 & 0.33 & \\
\hline
\end{tabular}

ECOG PS, Eastern Cooperative Oncology Group Performance Status; PSA, prostate specific antigen.

$<50 \mathrm{ng} / \mathrm{dL}),{ }^{11}$ was 21.4 months (IQR 7-27). One hundred and fourteen $(16.6 \%)$ patients received palliative chemotherapy, in the form of docetaxel, on diagnosis of CRPC. The median overall survival was 45 months (IQR 20-63), with PCa-specific mortality of $81.4 \%$. A poorer ECOG status ( $\mathrm{p}<0.01$, HR $2.08,95 \%$ CI 1.26 to 3.46), Gleason score $\geq 8$ ( $p<0.01$, HR $2.46,95 \%$ CI 1.61 to 3.78$)$, presence of visceral metastasis $(\mathrm{p}=0.04$, HR $1.67,95 \%$ CI 1.25 to $2.19)$ and high volume bone metastasis $(\mathrm{p}<0.01$, HR 1.84 , 95\% CI 1.48 to 2.38 ) were independent predictors of poorer overall survival (table 4 and figure 2).

Interim 5 yearly analyses (table 5) reported reduced local palliative treatment (from $48.1 \%$ between 1995 and 1999 to $23.2 \%$ between 2010 and 2014) but similar rates of skeletal fractures. There was improved compliance with hormonal therapy (from $86.8 \%$ between 1995 and 1999 to $99.3 \%$ between 2010 and 2014), with medical castration gradually replacing surgical orchidectomy $(p<0.01)$. Uptake of palliative chemotherapy at CRPC showed improvement from $9.3 \%(1995-1999)$ to $20.7 \%$ (2010-2014) $\quad(p=0.03)$. Improved overall survival was observed in the latter time period as compared with the earlier cohort, from 41.6 months (1995-1999) to 47.8 months $(2010-2014)(\mathrm{p}=0.04)$ (figure 3).

\section{DISCUSSION}

According to data from the WHO, PCa is the fourth most common cancer worldwide, behind lung, breast and colorectal cancers. ${ }^{12}$ However, relative to the other three most common cancers, advanced PCa has the best 5-year survival rate of $30 \% .{ }^{13-16}$ It appears that the natural progression of mPCa is much slower compared with other metastatic malignancies. ${ }^{17}$ However, this is at the expense of higher morbidity and possibly a debilitating quality of life. Given the relatively longer disease trajectory and survival, these morbidities become important aspects of oncological care.
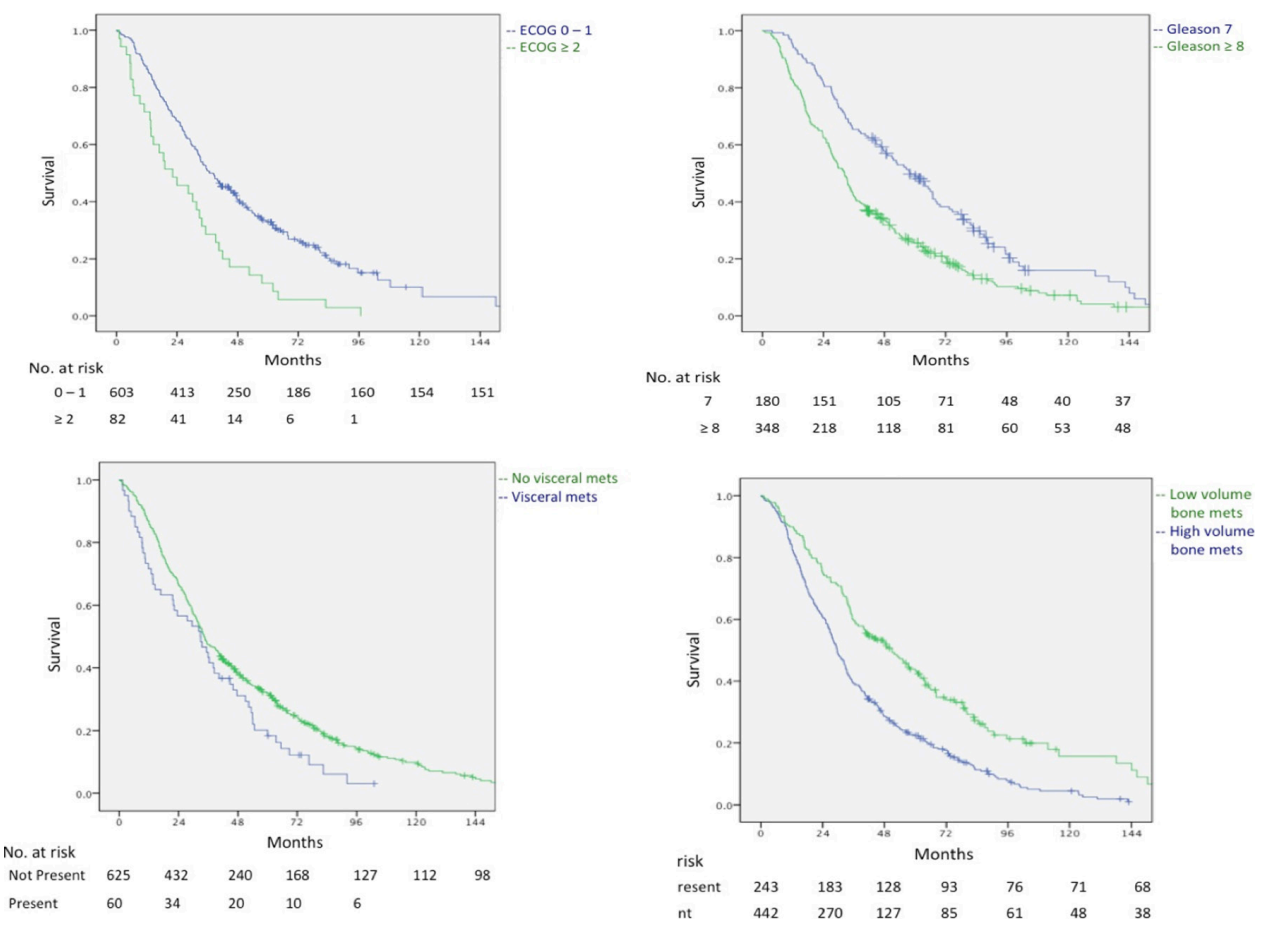

Figure 2 Predictors of overall survival. (A) ECOG status; (B) Gleason score; (C) presence of visceral metastasis; (D) presence of high volume bone metastasis. 
Table 5 Subgroup analyses of complication, treatments and survival outcomes as stratified by years

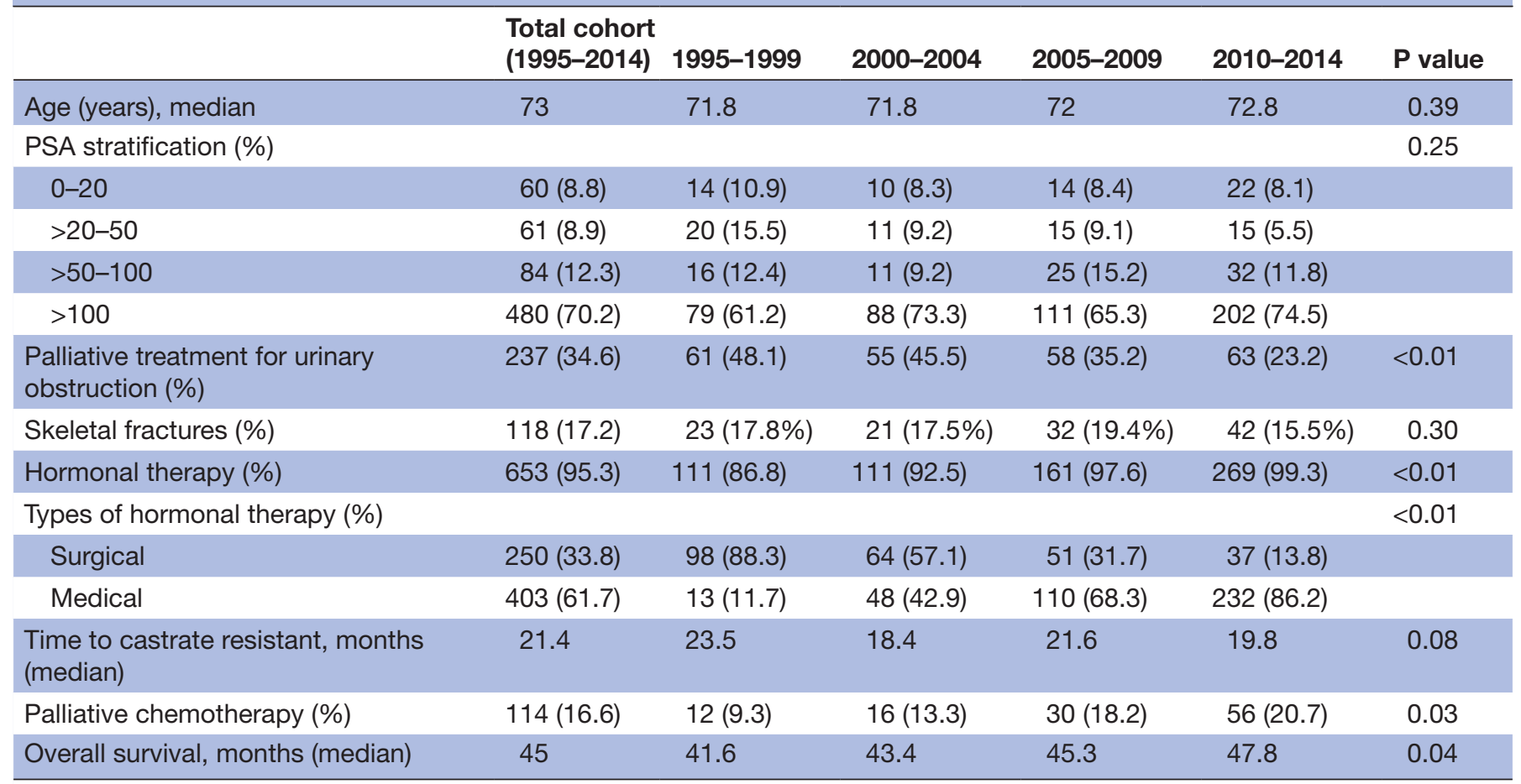

PSA, prostate specific antigen.

With regards to the prevalence of mPCa complications, our study found that close to 9 out of every 10 patients $(89.3 \%)$ were symptomatic, with the most common being bone pain $(81.2 \%)$. Local urinary complications were prevalent, which include urinary obstruction $(42.3 \%)$, haematuria $(27.0 \%)$ and urinary incontinence $(7.0 \%)$. Clinically, this roughly translated to one in every three patients $(34.6 \%)$ requiring local palliative intervention, of which 1 in 10 required repeated palliative interventionsan alarmingly high number. These numbers were similar to the ones reported in a retrospective study by Aus $e t a l,{ }^{18}$ in which more than a third of the patients $(37 \%)$ required

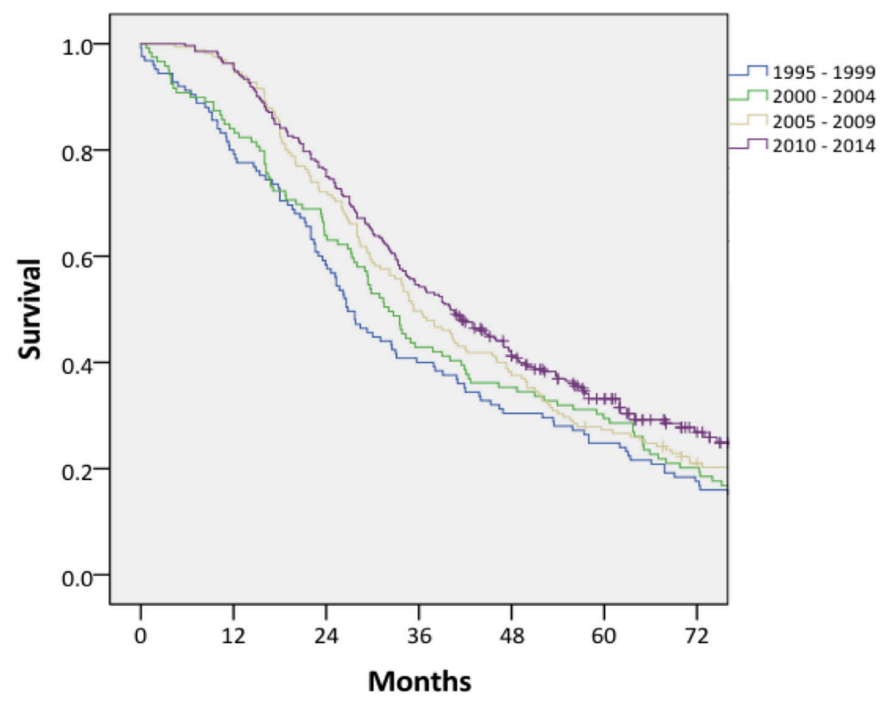

Figure 3 Overall survival across interim 5 yearly analyses. local palliative intervention-25\% underwent TURP and another $12 \%$ underwent upper urinary tract procedures. Oefelein ${ }^{19}$ also reported that $16 \%$ of patients had significant obstructive uropathy requiring local therapy.

Our findings showed that two factors-prostate volume (in $\mathrm{mL}$ measured using a trans-abdominal ultrasound probe) and baseline serum PSA levels-were independently prognostic of significant urinary obstruction requiring palliative treatments. Bearing in mind that benign prostatic hyperplasia $(\mathrm{BPH})$ may coexist with $\mathrm{mPCa}$, a prostate volume over $50 \mathrm{~mL}$ was found to be highly predictive for debilitating urinary obstruction ( $\mathrm{p}$ value 0.03 , HR $6.11,95 \%$ CI 4.21 to 26.22 ). Translating into clinical practice, regular evaluation of symptoms scores, coupled with objective assessments of transabdominal ultrasound measured prostate volume and uroflowmetry, may identify patients at high risks of local complications as a result of bladder outlet obstruction from advanced PCa. This study and others found a consistently high re-operation rate for local complications caused by advanced PCa. For channel TURP performed to alleviate bladder outlet obstruction from advanced prostate cancer, failure rates and repeat procedures were higher than conventional TURP for BPH, and with higher morbidities of bleeding and incontinence. A review by Mazur et $a l^{20}$ looking at the outcomes for obstructive symptoms from advanced PCa found a $22 \%$ re-operative rate, $5 \%$ urinary incontinence and another $5 \%$ with stress incontinence. A later study conducted by Crain et $a l^{21}$ found an even higher re-operative rate of $29 \%$, and more importantly, palliative TURP ultimately failed in $21 \%$ of 
patients requiring a long-term bladder catheterisation. These findings were further corroborated by Marszalek $e t$ $a l,{ }^{22}$ for which $25 \%$ of their patients who underwent palliative TURP necessitated repeated procedures, along with $11 \%$ needing permanent catheterisation and $10 \%$ experiencing urinary incontinence. Similarly, in this study, we found a re-operative rate of $9.7 \%$, although lower than the abovementioned literature.

In terms of systemic complications, this study showed that close to one in five patients $(17.2 \%)$ developed skeletal-related pathological fractures, a subset of SREs. The numbers were very similar to the $19 \%$ reported in a population-based analysis by Sathiakumar et at and not too far from the $10 \%$ reported in a Swedish cohort study by Nørgaard et $a l^{23}$ Our study had identified two independent prognostic factors for skeletal fractures-highvolume bone metastasis and poor ECOG performance status (ECOG PS). Interestingly, a study by Berruti et $a l^{24}$ similarly reported that heavy tumour load in bone (defined as disease extent in bone $>6$ sites) was significantly associated with the development of earlier SREs (RR $1.63,95 \%$ CI 1.32 to 2.00 ). This was further supported by the findings of an international, randomised, multicentre Phase III trial, ${ }^{25}$ which found that patients with more than three bone lesions at baseline had a 52\% increased risks of first on-study SRE (RR 1.523; 95\% CI=1.167 to 1.989; $\mathrm{p}=0.002)$. Furthermore, Owari et $a l^{26}$ also identified ECOG PS as one of the independent predictive factors for SREs, although it was a study focusing on risk factors for SREs in genitourinary cancers and not limited to PCa.

The mechanism of pathological fractures in mPCA is twofold: the combinatory direct destructive effect of bone metastases and hypogonadism-induced osteoporosis. These factors were assumed to synergistically impair bone stability. ${ }^{27}$ Current bone antiresorptive drugs ${ }^{728}$ (zoledronic acid and denosumab) were approved exclusively in CRPC and the added benefit of earlier initiation of these drugs in HSPC remained unclear. While the phase III CALGB $90202^{29}$ and PR 05 trials $^{30}$ demonstrated no reduction in skeletal events, these studies did not provide baseline or follow-up bone mineral density (BMD), which was an important determinant of osteoporosis and subsequent fracture risks. Nonetheless, given the alarmingly high prevalence of skeletal fractures, with a significant proportion occurring (median 17.2 months) prior to the progression of castrate-resistant disease (median 21.4 months), bone health remained a clinically important aspect of disease management in patients with HSPC. The data from this study alluded that certain HSPC patients, who might potentially be at higher risks of developing skeletal fractures (high volume bone metastasis or poor performance status), be considered for routine baseline BMD screening, and earlier initiation of antiresorptive therapies might be beneficial in this particular subgroup.

In terms of overall survival, a Gleason score of $\geq 8$, presence of high-volume bone metastasis, presence of visceral metastasis and poorer ECOG PS $\geq 2$ were found to be independent predictors for poorer outcomes, reflecting consistency in contemporary literature. ${ }^{31} 32$ Notably, these same factors were also important determinants for the early initiation of newer antiandrogens and chemotherapy in HSPC. ${ }^{33} 34$ Lastly, over these two decades (1995-2014), it was apparent that the incidence of de novo mPCa being referred to our institution had risen, from 129 (1999-2004) to 271 (2009-2014). This may reflect the changing referral patterns as our institution now represents the largest healthcare cluster within Singapore. We had demonstrated better compliance with ADT (86.8\%-99.3\%), with medical castration replacing surgical orchidectomy as the primary form of androgen suppression. Despite the higher costs, medical castration was favoured in a view of the various psychological and cosmetic concerns with surgical orchidectomy. Fortunately, there had been a decrease in palliative treatments for significant urinary obstruction. We hypothesised that improved health literacy may have translated to earlier health-seeking behaviours. Improved compliance with ADT would have facilitated better local disease control. In CRPC, the initiation of chemotherapy had shown improvement but continued to represent a small proportion of patients $(\sim 16 \%)$, which reflected the persistent aversion towards chemotherapy, particularly in Asian societies. While the time to castrate resistance remains consistent, overall survival for PCa has improved, from a median of 41.6 months (1999-2004) to 47.8 months (2009-2014). This could be the effect of better ADT compliance and initiation of chemotherapy in the treatment of advanced PCa.

We acknowledge several limitations in this study. The data were derived from a single tertiary institution, and the analysis was retrospective in nature. Several related outcomes could not be adequately measured. For instance, we were not able to completely capture data on patients who required interventions (surgical or radiation) for bone metastases, which were important determinants of SREs. Also, the study period precluded the availability of validated quality-of-life assessment tools, which would have better reflected the patients' well being. Selection bias remained present due to loss to follow-up. However, given that our institution represents the largest public healthcare cluster within Singapore, with the largest oncological departments, the abovementioned selection bias is largely insignificant.

\section{Conclusion}

The present study had demonstrated that morbidities and complications from mPCa are more common and debilitating than we thought. With the incidence of mPCa likely to rise in tandem with an ageing world population and given the improving survivorship of patients with $\mathrm{mPCa}$, both patients and clinicians alike will have to contend with significant morbidities during the course of the disease. The data from this study suggests that the risk factors such as prostate volume, baseline PSA at presentation; high volume bone metastasis and poor ECOG PS prognosticate for local obstructive urinary complications 
and skeletal fractures, respectively. Early recognition of these predictive factors will guide clinicians in early detection that can lead to optimising palliative treatment for these patients.

Contributors YGT: Project development, data collection or management, data analysis, manuscript writing. LP and RP: Data collection or management, manuscript writing. FK and KC: Manuscript writing, critical revision of the manuscript. HHH: Data collection or management, data analysis. KJT, WL, CC and $\mathrm{HH}$ : Project development, critical revision of the manuscript. JY: Project development, data analysis, critical revision of the manuscript.

Funding The authors have not declared a specific grant for this research from any funding agency in the public, commercial or not-for-profit sectors.

Competing interests None declared.

Patient consent for publication Not required.

Ethics approval All procedures performed in studies involving human participants were in accordance with the ethical standards of the institutional and/or national research committee (SingHealth Institutional Review Board 2009/1053/D) and with the 1964 Helsinki declaration and its later amendments or comparable ethical standards.

Provenance and peer review Not commissioned; externally peer reviewed.

Data availability statement All data relevant to the study are included in the article or uploaded as supplementary information. No additional data available.

Open access This is an open access article distributed in accordance with the Creative Commons Attribution Non Commercial (CC BY-NC 4.0) license, which permits others to distribute, remix, adapt, build upon this work non-commercially, and license their derivative works on different terms, provided the original work is properly cited, appropriate credit is given, any changes made indicated, and the use is non-commercial. See: http://creativecommons.org/licenses/by-nc/4.0/.

\section{ORCID iDs}

Leonard Pang http://orcid.org/0000-0002-7285-7519

Randy Poon http://orcid.org/0000-0002-4417-4323

\section{REFERENCES}

1 National Registry of Diseases Office. Singapore cancer registry annual Registry report 2015 - statistics, 2015. Available: https:// www.nrdo.gov.sg/publications/cancer [Accessed 29 May 2019].

2 Siegel RL, Miller KD, Jemal A. Cancer statistics, 2017. CA Cancer J Clin 2017;67:7-30.

3 Chen R, Ren S, Yiu MK, et al. Prostate cancer in Asia: a collaborative report. Asian J Urol 2014;1:15-29.

4 Bill-Axelson A, Holmberg L, Ruutu M, et al. Radical prostatectomy versus watchful waiting in early prostate cancer. $N$ Engl J Med 2011;364:1708-17.

5 Zelefsky MJ, Reuter VE, Fuks Z, et al. Influence of local tumor control on distant metastases and cancer related mortality after external beam radiotherapy for prostate cancer. J Urol 2008;179:1368-73.

6 Corriere JN, Cornog JL, Murphy JJ, et al. Prognosis in patients with carcinoma of the prostate. Cancer 1970;25:911-8.

7 Saad F, Gleason DM, Murray R, et al. Long-Term efficacy of zoledronic acid for the prevention of skeletal complications in patients with metastatic hormone-refractory prostate cancer. J Nat/ Cancer Inst 2004;96:879-82.

8 Weinfurt KP, Li Y, Castel LD, et al. The significance of skeletal-related events for the health-related quality of life of patients with metastatic prostate cancer. Ann Oncol 2005;16:579-84.

9 Sathiakumar N, Delzell E, Morrisey MA, et al. Mortality following bone metastasis and skeletal-related events among men with prostate cancer: a population-based analysis of US Medicare beneficiaries, 1999-2006. Prostate Cancer Prostatic Dis 2011;14:177-83.

10 Sweeney CJ, Chen Y-H, Carducci M, et al. Chemohormonal therapy in metastatic hormone-sensitive prostate cancer. N Engl J Med Overseas Ed 2015;373:737-46.

11 Scher HI, Halabi S, Tannock I, et al. Design and end points of clinical trials for patients with progressive prostate cancer and castrate levels of testosterone: recommendations of the prostate cancer clinical trials Working group. J Clin Oncol 2008;26:1148-59.

12 World Health Organization. Cancer, 2019. Available: https://www. who.int/news-room/fact-sheets/detail/cancer [Accessed 29 May 2019].

13 Cancer.Net. ASCO. Prostate cancer: statistics, 2019. Available: https://www.cancer.net/cancer-types/prostate-cancer/statistics [Accessed 29 May 2019].

14 Cancer.Net. ASCO. Lung Cancer - Non-Small Cell: Statistics, 2019. Available: https://www.cancer.net/cancer-types/lung-cancer-nonsmall-cell/statistics [Accessed 29 May 2019].

15 Cancer.Net. ASCO. Breast cancer: statistics, 2019. Available: https:// www.cancer.net/cancer-types/breast-cancer/statistics [Accessed 29 May 2019].

16 Cancer.Net. ASCO. Colorectal cancer: statistics, 2019. Available: https://www.cancer.net/cancer-types/colorectal-cancer/statistics [Accessed 29 May 2019].

17 Riihimäki $\mathrm{M}$, Thomsen $\mathrm{H}$, Hemminki $\mathrm{A}$, et al. Comparison of survival of patients with metastases from known versus unknown primaries: survival in metastatic cancer. BMC Cancer 2013;13:36.

18 Aus G, Hugosson J, Norlén L, et al. Need for hospital care and palliative treatment for prostate cancer treated with noncurative intent. J Urol 1995;154:466-9.

19 Oefelein MG. Prognostic significance of obstructive uropathy in advanced prostate cancer. Urology 2004;63:1117-21.

20 Mazur AW, Thompson IM. Efficacy and morbidity of "channel" TURP. Urology 1991;38:526-8.

21 Crain DS, Amling CL, Kane CJ. Palliative transurethral prostate resection for bladder outlet obstruction in patients with locally advanced prostate cancer. J Urol 2004;171:668-71.

22 Marszalek M, Ponholzer A, Rauchenwald M, et al. Palliative transurethral resection of the prostate: functional outcome and impact on survival. BJU Int 2007;99:56-9.

23 Nørgaard M, Jensen Annette Østergaard, Jacobsen JB, et al. Skeletal related events, bone metastasis and survival of prostate cancer: a population based cohort study in Denmark (1999 to 2007). J Urol 2010;184:162-7.

24 Berruti A, Tucci M, Mosca A, et al. Predictive factors for skeletal complications in hormone-refractory prostate cancer patients with metastatic bone disease. Br J Cancer 2005;93:633-8.

25 Tchekmedyian NS, Chen Y-M, Saad F, et al. Disease progression increases the risk of skeletal-related events in patients with bone metastases from castration-resistant prostate cancer, lung cancer, or other solid tumors. Cancer Invest 2010;28:849-55.

26 Owari T, Miyake M, Nakai Y, et al. Clinical features and risk factors of skeletal-related events in genitourinary cancer patients with bone metastasis: a retrospective analysis of prostate cancer, renal cell carcinoma, and urothelial carcinoma. Oncology 2018;95:170-8.

27 Todenhöfer T, Stenzl A, Hofbauer LC, et al. Targeting bone metabolism in patients with advanced prostate cancer: current options and controversies. Int J Endocrinol 2015;2015:838202

28 Fizazi K, Carducci M, Smith M, et al. Denosumab versus zoledronic acid for treatment of bone metastases in men with castrationresistant prostate cancer: a randomised, double-blind study. Lancet 2011;377:813-22.

29 Smith MR, Halabi S, Ryan CJ, et al. Randomized controlled trial of early zoledronic acid in men with castration-sensitive prostate cancer and bone metastases: results of CALGB 90202 (Alliance). J Clin Oncol 2014;32:1143-50.

30 Dearnaley DP, Sydes MR, Mason MD, et al. A double-blind, placebo-controlled, randomized trial of oral sodium clodronate for metastatic prostate cancer (MRC PR05 trial). J Natl Cancer Inst 2003;95:1300-11.

31 Fizazi K, Massard C, Smith M, et al. Bone-Related parameters are the main prognostic factors for overall survival in men with bone metastases from castration-resistant prostate cancer. Eur Urol 2015;68:42-50.

32 Halabi S, Small EJ, Kantoff PW, et al. Prognostic model for predicting survival in men with hormone-refractory metastatic prostate cancer. Clin Oncol 2003;21:1232-7.

33 ECOG-ACRIN cancer research group. E3805: ChemoHormonal therapy versus androgen ablation randomized trial for extensive disease in prostate cancer (CHAARTED) ClinicalTrials.gov identifier NCT00309985; 2014.

34 Fizazi K, Tran N, Fein L, et al. Abiraterone acetate plus prednisone in patients with newly diagnosed high-risk metastatic castrationsensitive prostate cancer (latitude): final overall survival analysis of a randomised, double-blind, phase 3 trial. Lancet Oncol 2019;20:686-700. 